\title{
The potential significance of two coagulation defects: Prekallikrein Deficiency and Arg304Gln (FVII Padua) frequently found among African-Americans
}

\section{Girolami Antonio* and Ferrari Silvia \\ University of Padua Medical School Department of Medicine, Padua, Italy}

\section{Dear Sir,}

Sporadic observations have suggested that Prekallikrein (PK) deficiency occurs frequently among African-Americans [1,2].

A recent comparative study on reported cases has confirmed the prevalence of PK deficiency among African-Americans as compared to the general American population [3].

It is interesting to note that other contact phase defects have been described in African-Americans namely, High Molecular Weight Kininogen (HMWK) deficiency or Fitzgerald trait [4]. Total KN (Willliams defect) defect has been described instead in Caucasians [5].

As far as FXII deficiency is concerned no information about ethnic preference is available. Mr Hageman was Caucasian [6]. Patients with PK deficiency show no bleeding tendency but seem to be frequently associated with hypertension and hypertension related disorders [7].

The role of this defect on the frequent increase of CVD found among African-Americans is unknown.

It is interesting to note that no increased prevalence of FXII deficiency is present among African-Americans.

The evaluation of the cases with total kininogen (KN) or HMWK deficiency is still unclear due to the rarity of the defects [8].

As far as FVII deficiency, is concerned, it has been demonstrated that the Arg304Gln mutation in exon 8, originally described in Padua, is frequent among African-Americans [9-12]. No other FVII defect has a similar behavior. Incidentally, the index patient with FVII deficiency described by Alexander et al in 1950 was Caucasian and showed a different mutation [13].

PK and, perhaps, the HMWK deficiencies are or seem more frequent among African-Americans [1,2]. Factor VII Padua, a Type 2 variant, due to Arg304Gln mutation in exon 8, seems also frequent among African-Americans [9-12].

PK and FVII are controlled by different genes, on different chromosomes.

Interestingly, there is no report of patient with both defects at the homozygote or at the heterozygote level.

However, due to the fact that PK deficient patients do not bleed and that patients with the FVII Arg304Gln mutation have only a mild bleeding tendency or are also asymptomatic, we cannot exclude that patients with a combined defect of these two disorders do exist. Because of the lack or paucity of symptoms they could go undetected [14].

If one takes into account the other side of the homeostatic balance, namely thrombosis, it may be, at least on theoretical grounds, more likely that PK deficiency is associated with hypertension related disorders $[15,16]$ while FVII Padua has been demonstrated to show an increased risk of venous thrombosis [17]. On the contrary, these seem rare in PK deficiency [16].

The rarity of the conditions has prevented long term observational studies and therefore no sure conclusion can be drawn.

Tentatively it may be stated that PK deficiency is associated with arterial disorders whereas the FVII Arg304Gln mutation is mainly associated with venous thrombosis $[3,17]$.

The African American population is known to present frequent cardiovascular disorders [18-20]. The potential role of these two mutations has never been thoroughly investigated.

Sporadic reports and limited series of case studies indicate that both defects are frequent among African-Americans $[1,2,9,12]$.

It would be useful to progress in this investigation in order to ascertain weather these defects are responsible, at least in part, for the increased prevalence of cardiovascular disorders seen among this population.

\section{Conflicts of interest}

The authors declare that they have no conflict of interest.

\section{References}

1. Sollo DG, Sleem A (1985) Prekallikrein (Fletcher Factor) deficiency. Ann Clin Lab Sci 15 : 279-285

2. Saito H (1987) Contact Factors in Health and Disease. Semin Thromb Hemost 13: 36-49.

3. Girolami A, Ferrari S, Cosi E, Girolami B (2019) Increased prevalence of reported cases of congenital Prekallikrein deficiency among African Amricans as compared with the general population of the USA. Clin Appl Thromb Hem [Submitted].

4. Waldmann R, Abraham JP, Rebuck JW, Caldwell J, Saito H, et al. (1975) Fitzgerald factor: a hitherto unrecognised coagulation factor. Lancet 1: 949-951.

*Correspondence to: Antonio Girolami, University of Padua Medical School, Via Ospedale 105 Padua-35128, Italy, Tel: 0039-049-8213026; Fax: 0039-049657391; Email: antonio.girolami@unipd.it

Received: December 06, 2019; Accepted: January 10, 2020; Published: January 13,2020 
5. Colman RW, Bagdasarian A, Talamo RC, Scott CF, Seavey M, et al. (1975) Human kininogen deficiency with diminished levels of plasminogen proactivator and prekallikrein associated with abnormalities of the Hageman factor-dependent pathways. J Clin Invest 56: 1650-1662.

6. Ratnoff OD, Colopy JE (1955) A familial hemorrhagic trait associated with a deficiency of a clot-promoting fraction of plasma. J Clin Invest 34: 602-613.

7. Girolami A, Ferrari S, Cosi E, Sambado L, Girolami B (2015) Prevalence of hypertension and its complications in congenital prekallikrein deficiency: analysis of all reported cases and clinical significance. Blood Coagul Fibrinolysis 26: 560-563.

8. Colman RW (2001) Contact activation pathway: inflammatory,fibrinolytic, anticoagulant, antiadhesive and antiangiogenicactivities. In: Colman RW, Hirsh J, Marden VJ, Clowes AW, George JM (Eds) Thrombosis and haemostasis, (4th Edn) Lippin-cott, Philadelphia.

9. Kirkel D, Lin TW, Fu SW (2010) Asymptomatic factor VII deficiency: Gene analysis and structure-function relationships. Blood Coagul Fibrinolysis 21: 91-94.

10. Sabharwal AK, Kuppuswamy MN, Foster DC (1992) Factor VII deficiency (FVII Richmond, R304Q Mutant) associated with thrombosis. Circulation 86: 679.

11. Shurafa MS, Kumar A, Fair DS (1993) The molecular defect in factor VII Detroit is due to substitution of $\operatorname{Arg}$ (304) by Glu. FASEB J 7: 115.

12. Triplett DA, Brandt JT, Batard MA (1985) Hereditary factor VII deficiency: Heterogeneity defined by combined functional and immunochemical analysis. Blood 66: $1284-1287$.
13. Alexander B, Goldstein R, Landwehr G, Cook Cd (1951) Congenital SPCA deficiency: a hitherto unrecognized coagulation defect with hemorrhage rectified by serum and serum fractions. J Clin Invest 30: 596-608.

14. Girolami A, Ferrari S, Cosi E, Sambado L, Girolami B (2015) Prevalence of hypertension and its complications in congenital prekallikrein deficiency: analysis of all reported cases and clinical significance. Blood Coagul Fibrinolysis 26: 560-563.

15. Girolami A, Scarparo P, Candeo N, Lombardi AM (2010) Congenital prekallikrein deficiency. Expert Rev Hematol 3: 685-695.

16. Girolami A, Ferrari S, Cosi E, Lombardi AM (2018) A structure-function analysis in patients with prekallikrein deficiency. Hematology 23: 346-350.

17. Girolami A, Cosi E, Ferrari S, Girolami B, Randi ML (2019) Thrombotic events in homozygotes with a proven or highly probable Arg304Gln Factor VII mutation (FVII Padua) 1): only limited replacement therapy is needed in case of surgery. Cardiovasc Hematol Disord Drug Targets 19: 233-238.

18. Mendy VL1,2, Vargas R3, Payton M1,4, et al. (2019) Trends in the Stroke Death Rate Among Mississippi Adults, 2000-2016. Prev Chronic Dis 16: E21. [Crossref]

19. Waldron FA, Benenson I, Jones-Dillon SA, Zinzuwadia SN, Adeboye AM, et al (2019) Prevalence and risk factors for hypertensive crisis in a predominantly African American inner-city community. Blood 28: 114-123.

20. Colantonio LD, Monda KL, Rosenson RS, Brown TM, Mues KE, et al. (2019) Characteristics and Cardiovascular Disease Event Rates among African Americans and Whites Who Meet the Further Cardiovascular Outcomes Research with PCSK9 Inhibition in Subjects with Elevated Risk (FOURIER) Trial Inclusion Criteria. Cardiovasc Drugs Ther 33: 189-199.

Copyright: (C2020 Antonio G. This is an open-access article distributed under the terms of the Creative Commons Attribution License, which permits unrestricted use, distribution, and reproduction in any medium, provided the original author and source are credited. 